Tropical Journal of Pharmaceutical Research February 2012; 11 (1): 36-42

(C) Pharmacotherapy Group,

Faculty of Pharmacy, University of Benin

Benin City, 300001 Nigeria.

All rights reserved.

Available online at http://www.tjpr.org

Research Article

http://dx.doi.org/10.4314/tjpr.v11i1.5

\title{
Anti-Stress and Anti-Amnesic Effects of Coriandrum sativum Linn (Umbelliferae) Extract - an Experimental Study in Rats
}

\section{Sushruta Koppula* and Dong Kug Choi}

College of Biomedical and Health Sciences, Department of Biotechnology, Konkuk University, Chungju, Republic of Korea.

\begin{abstract}
Purpose: Coriandrum sativum Linn. (Umbelliferae, C. sativum) is cultivated throughout the world for its use as spice and as a folk medicine. This study deals with the anti-stress and anti-amnestic properties of $C$. sativum extract in rats.

Methods: Urinary levels of vanillylmandelic acid (VMA) and ascorbic acid were used to evaluate antistress activity in rats, while conditioned avoidance response test in normal and scopolamine-induced amnesic rats was used to evaluate anti-amnesic effects. C. sativum extract was also evaluated for its antioxidant activities by inhibition of lipid peroxidation in brain and liver homogenates of the rats.

Results: Daily administration of C. sativum extract (100, 200 and $300 \mathrm{mg} / \mathrm{kg}$ body weight) $1 \mathrm{~h}$ prior to induction of stress significantly decreased the stress-induced urinary levels of VMA from $382.79 \pm 10.70$ to $350.66 \pm 15.15,291.21 \pm 16.53$ and $248.86 \pm 13.56 \mu \mathrm{g} / \mathrm{kg} / 24 \mathrm{~h}$ and increased the ascorbic acid excretion levels from $66.73 \pm 9.25$ to $69.99 \pm 7.37,105.28 \pm 13.74$ and $135.32 \pm 12.54 \mu \mathrm{g} / \mathrm{kg} / 24 \mathrm{~h}$ at 100,200 and $300 \mathrm{mg} / \mathrm{kg}$, respectively, in a dose-dependent fashion without affecting the normal levels in control groups. The amnesic deficits (acquisition, retention and recovery) induced by scopolamine $(1 \mathrm{mg} / \mathrm{kg}$, i.p.) in rats was reversed by C. sativum dose dependently. The extract also inhibited lipid peroxidation in both rat liver and brain to a greater extent than the standard antioxidant, ascorbic acid.

Conclusion: C. sativum may be useful remedy in the management of stress and stress related disorders on account of its multiple actions such as anti-stress, anti-amnestic and antioxidant effects.
\end{abstract}

Keywords: C. sativum, Stress, Lipid peroxidation, Vanillylmandelic acid, Memory. 


\section{INTRODUCTION}

Stress is experienced by every individual and is a reaction of mind and body resulting in threatened homeostasis. Extreme stress may lead to the pathogenesis of a stream of disease conditions including hypertension, peptic ulcer, diabetes, immunosuppression, reproductive dysfunctions, metabolic and endocrine disorders [1]. Research has revealed that stress impairs brain functioning, which leads to memory loss and can negatively affect cognitive skills leading to the pathogenesis of various neurodegenerative disorders [2,3]. Further, overload of stress build up the free radicals and induce potential damage to neuronal receptors and damage a variety of other organ tissues [4]. Thus agents that scavenge free radicals may have great potential in mitigation of these disorders/diseases.

Spices are used not only to add flavor, color and nutritional values to food, but also to treat various diseases [5]. Coriandrum sativum Linn. (Umbelliferae, C. sativum), commonly known as coriander, is a widely cultivated spice all over the world. Traditionally, $C$. sativum is used in the disorders of digestive, respiratory, urinary, convulsions, insomnia and anxiety. Pharmacologically, C. sativum was reported to possess antidiabetic, hepatoprotective, antimutagenic, antihypertensive, antioxidant, anxiolytic, antimicrobial activity and heavy metal detoxification [6-8].

The major chemical components identified in C. sativum are flavonoids, polyphenols and carotenoids $[9,10]$. Despite the potential medicinal benefits of $C$. sativum, the stress relieving and memory enhancing effects have not been fully investigated. The aim of the present study was to assess the anti-stress and anti-amnesic effects of aqueous extract of $C$. sativum in vivo, and to correlate the anti-stress and anti-amnesic effects with in vitro inhibition of lipid peroxidation.

\section{EXPERIMENTAL}

\section{Chemicals}

Vanillylmandelic acid (VMA) and scopolamine butyl bromide (SBB) were purchased form Sigma Chemical Company, St. Louis, MO, USA. Ascorbic acid was purchased from Loba Chemie, Mumbai. All other reagents used were of analytical grade. Stock solutions of all chemicals were prepared in distilled water and the dilutions were made fresh on the day of the experiment.

\section{Preparation of extract}

Dried fruit material of $C$. sativum $(1 \mathrm{~kg})$ was obtained from a local market in Vijayawada, India and the authenticity of the fruit material was confirmed by taxonomist Dr. Hemadri K, Regional Research Institute, India. A voucher specimen (CS-2003) was kept in our department herbarium for future reference. The material was powdered and extracted with boiling water $(5 \mathrm{~L})$ for $30 \mathrm{~min}$ by Soxhlet technique. The filtrate was evaporated at < $70{ }^{\circ} \mathrm{C}$ in a vacuum dryer to give a final yield of 108.69 g. C. sativum was completely solubilized in distilled water for use in in vivo and in vitro experiments respectively

\section{Animals}

Wistar rats of either sex, obtained from Ghosh Enterprises, Kolkata were housed in an air-conditioned animal room at $23 \pm 2{ }^{\circ} \mathrm{C}$ with $12 / 12 \mathrm{~h}$ light/ dark photoperiod, and free access to water and laboratory rat chow. Animals were kept for seven days in laboratory for habituation. All animal experiments were performed in accordance and approval with our Institutional Animal Ethics Committee (Regd. No. 516/01/A/CPCSEA) following the guidelines of the Committee for the Purpose of Control and Supervision of Experiments on Animals (CPCSEA), Government of India and the International Guidelines for Handling of Laboratory Animals [11]. 


\section{Evaluation of anti-stress activity}

Induction of stress was carried out using the forced swimming test in rats [12]. The animals were divided into four groups, each consisting of six animals of either sex, in metabolic cages that were designed to facilitate the collection of urine. $24 \mathrm{~h}$ urine samples from each group were collected into two different beakers using an inverted ' $Y$ ' tube fixed at the bottom of each metabolic cage. One end of the tube received urine into a beaker containing $5 \mathrm{ml}$ of $10 \%$ oxalic acid and then passed on for spectrophotometric determination of ascorbic acid at $550 \mathrm{~nm}$ [13]. The other end of the tube received and moved urine into a beaker containing $0.5 \mathrm{ml}$ of $6 \mathrm{~N}$ hydrochloric acid for determination of vanillylmandellic acid (VMA) spectrophotometrically at $360 \mathrm{~nm}$ [14].

The experimental protocol was divided into four phases. In the first phase of the experiment, $24 \mathrm{~h}$ urine samples were collected in all the 4 groups and subjected to analysis for both VMA and ascorbic acid separately and the values were recorded for 5 consecutive days. In the second phase, the animals in each group were individually subjected to fresh water swimming stress [12]. In this method, the rats were forced to swim until they were exhausted (usually after 3-4 min) in a cylindrical vessel of height 60 $\mathrm{cm}$ and diameter $45 \mathrm{~cm}$ containing water at room temperature $\left(28{ }^{\circ} \mathrm{C}\right)$. Water depth was always maintained at $40 \mathrm{~cm}$. The $24 \mathrm{~h}$ urinary levels of VMA and ascorbic acid under these stressed conditions were determined daily as outlined above for 5 consecutive days. The third phase of the experiment consisted of administration of $C$. sativum extract to the animals following recovery to normal condition (usually in 3-4 days). Groups II, III and IV were administered orally with C. sativum (dissolved in distilled water) at daily doses of 100, 200 and 300 $\mathrm{mg} / \mathrm{kg}$ body weight respectively for 5 consecutive days, while group I served as control and received only distilled water. $24 \mathrm{~h}$ urine samples were collected and the levels of both VMA and ascorbic acid were determined. The final phase of the experiment consisted of evaluating the influence of $C$. sativum extract on stressinduced changes in the animals after a recovery period of one week. Groups II, III and IV were administered $C$. sativum by oral gavage at daily doses of 100,200 and 300 $\mathrm{mg} / \mathrm{kg}$, respectively, one hour to the daily induction of stress for 5 consecutive days. Group I served as control received only distilled water. Urine samples $(24 \mathrm{~h})$ were collected and analyzed for VMA and ascorbic acid for 5 consecutive days to assess the influence of the extract on stress-induced biochemical changes.

\section{Evaluation of anti-amnesic activity}

This experiment was evaluated by conditioned avoidance response (CAR) technique in rats using Cook's pole climbing apparatus, Techno, India [15]. The rats were divided into 4 groups of 5 animals each. Groups II, III and IV were administered orally with 100,200 and $300 \mathrm{mg} / \mathrm{kg}$, respectively of C.sativum (dissolved in distilled water) while animals in group I were served as control and received only distilled water. After 90 minutes, all the animals were subjected to a training schedule individually by placing them inside the Perspex chamber of the apparatus. After an acclimatization period of $5 \mathrm{~min}$ in the chamber, a buzzer was given followed by a shock through the grid floor. The rat had to jump on to the pole (shock-free zone) to avoid foot shock. Jumping on the pole functionally terminates the shock and this was classified as an escape while such jumping prior to the onset of the shock was considered as avoidance. The session was terminated after completion of 60 trials with an interval of 20-30 seconds between trials. This procedure was repeated at $24 \mathrm{~h}$ intervals until all groups reach 95 to $99 \%$ avoidance. Following the attainment of complete training for a particular group, the animals were treated with a single dose of scopolamine butyl bromide (1 $\mathrm{mg} / \mathrm{kg}$, i.p.) to induce amnesia, 30 min before the next day 
dosing with the extract. The training schedule was continued further with the daily doses of the extract and vehicle until the rats returned to normal level from scopolamine-induced amnesia.

\section{Inhibition of lipid peroxidation in rat liver and brain (TBARS assay)}

Rats weighing between 150-200 g were sacrificed by spinal traction and liver was excised and washed in ice-cold Tris- $\mathrm{HCl}$ buffer (0.1M, pH 7.4), and cytosolic samples of liver homogenate were prepared by centrifuging at $10,000 \mathrm{rpm}$ for $30 \mathrm{~min}$ at $4{ }^{\circ} \mathrm{C}$. Reaction mixture $(0.5 \mathrm{ml})$ containing rat liver homogenate $(0.1 \mathrm{ml}, 25 \% \mathrm{w} / \mathrm{v})$ in Tris- $\mathrm{HCl}$ buffer (40 mM, pH 7.0), KCl (30 mM), ferrous ion $(0.16 \mathrm{mM})$, and ascorbic acid $(0.06 \mathrm{mM})$ were incubated for $1 \mathrm{~h}$ at $37{ }^{\circ} \mathrm{C}$ in the presence and absence of various concentrations of $C$. sativum extract. The lipid peroxide formed was measured by TBARS formation [16]. Incubation mixtures $(0.4 \mathrm{ml})$ were treated with sodium dodecyl sulfate $(8.1 \%, 0.2 \mathrm{ml})$, thiobarbituric acid $(0.8 \%, 1.5$ $\mathrm{ml})$, and acetic acid (20\%, $1.5 \mathrm{ml}, \mathrm{pH} 3.5)$. The total volume was then made up to $4 \mathrm{ml}$ with distilled water and kept in a water bath at $100{ }^{\circ} \mathrm{C}$ for $1 \mathrm{~h}$. On cooling, $1 \mathrm{ml}$ of distilled water and $5 \mathrm{ml}$ of a mixture of $\mathrm{n}$-butanol and pyridine $(15: 1 \mathrm{v} / \mathrm{v})$ were added and vortexed. After centrifugation, the absorbance of the organic layer was measured at $532 \mathrm{~nm}$. The percentage inhibition of lipid peroxidation was determined by comparing the results of the test compound with those of the control not treated with the extract. The same procedure was followed with rat whole brain homogenate. The $50 \%$ inhibition values were derived from a plot of quantity $(\mu \mathrm{g})$ against optical density.

\section{Statistical analysis}

The results are expressed as mean \pm S.E.M. Student's paired $t$-test using GraphPad software was implemented for statistical analysis. In all cases, $p<0.05$ was considered statistically significant.

\section{RESULTS}

As shown in Figs 1 and 2 , a significant increase $(p<0.05)$ in urinary levels of VMA and decrease in ascorbic acid excretion levels was observed in animals subjected to forced swim stress when compared to the normal basal levels in control animals. The altered levels returned to normal basal levels in three to four days after withdrawal of stress. The extract treated groups under normal condition produced no significant change in the excretion of VMA and ascorbic acid compared to normal basal levels. Treatment with extract $(100,200$ and 300 $\mathrm{mg} / \mathrm{kg}$ ) one hour prior to the induction of stress significantly inhibited increase in urinary VMA levels dose-dependently (Fig 1). In contrast, administration of the extract one hour prior to the induction of stress significantly inhibited the decrease in urinary levels of ascorbic acid (Fig 2). The inhibition of the increase in VMA levels and decrease in ascorbic acid levels were dose-dependent $(p<0.05)$.

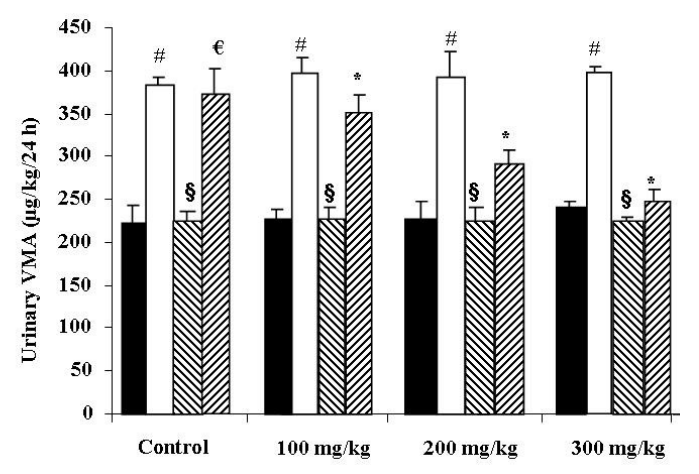

Fig 1: Influence of $C$. sativum extract on the $24 \mathrm{~h}$ urinary levels of VMA in normal and stressinduced rats (mean \pm SEM, $n=6$ ). ${ }^{*} p<0.001$ compared to normal condition of the corresponding groups. ${ }^{*} p<0.05$, compared with stressed condition of the corresponding groups. ${ }^{\S}$ No significant difference from normal condition of the corresponding groups. ${ }^{\epsilon}$ No significant difference from stressed condition. Significance was determined using Student's $t$-test, $p<0.05$ was considered statistically significant.

$\square=$ Group I (Untreated), $\square$ Group II (Stress), $\mathbf{\Delta}=$ Group III (Extract alone), $\boldsymbol{Z}=$ Group IV (Extract + Stress). 


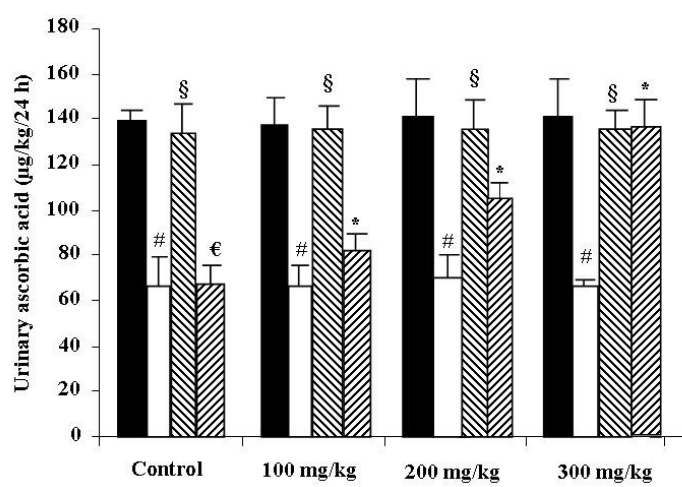

Fig 2: Effect of $C$. sativum extract on the $24 \mathrm{~h}$ urinary levels of ascorbic acid in normal and stress induced rats. Data are represented as mean \pm SEM $(n=6)$. ${ }^{*} p<0.001$, compared to normal condition of the corresponding groups. ${ }^{*} p<0.05$, compared with stressed condition of the corresponding groups. ${ }^{\S}$ No significant difference from normal condition of the corresponding groups. ${ }^{€}$ No significant difference compared to stressed condition. Significance was determined using Student's $t$-test, $\mathrm{p}<0.05$ was considered statistically significant.

= Group I (Untreated), $\square$ Group II (Stress), $\bar{\nabla}=$ Group III (Extract alone), $\mathbf{\nabla}=$ Group IV (Extract + Stress).

The CAR of rats administered with the extract increased gradually to $95 \%$ over seven to eleven days (Fig 3). The acquisition (time to achieve $95 \%$ CAR) for rats administered with the extract was dose- and time-dependent compared to vehicle treated (control) group which took 11 days for acquisition. The percent avoidance was always higher in the extract treated groups compared to vehicle treated (control) group. Animals receiving $300 \mathrm{mg} / \mathrm{kg}$ body weight of the extract took eight days while groups treated with 200 and $100 \mathrm{mg} / \mathrm{kg}$ doses of the extract required nine to ten days, respectively, to reach the point of acquisition. Administration of scopolamine produced amnesia as seen from reduction in the observed CAR. Amnesia was greater in the control group than in extract-treated groups. However, continued treatment with $C$. sativum produced better retention and recovery in a dose-dependent manner than the vehicletreated animals. Recovery from scopolamineinduced amnesia in the extract-treated groups took 3-4 days when compared to normal (control) group which took over 5 days.

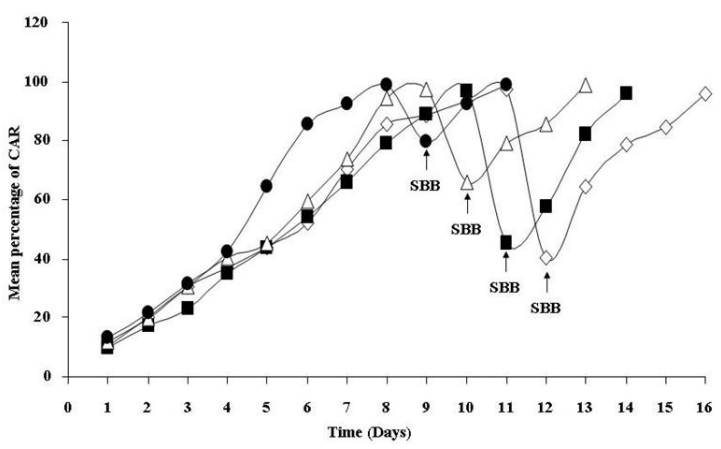

Fig 3: Effect of $C$. sativum extract on the mean percent of conditioned avoidance response after oral administration in rats. Scopolamine butyl bromide (SBB) was administered thirty minutes before the next day dosing with the extract after attaining complete acquisition. $\diamond=$ Control, $\mathbf{\square}=100$ $\mathrm{mg}, \Delta=200 \mathrm{mg}$ and $\bullet=300 \mathrm{mg}$.

The extract inhibited the producvtiuon of peroxides by the induction of $\mathrm{fe}^{2+} / \mathrm{ascorbate}$ in rat liver and brain homogenates in a dosedependent fashion (Fig. 4). The inhibition was higher in brain homogenate than in liver, indicating that it is more effective in brain. The quantity of the extract needed for $50 \%$ inhibition of lipid peroxides in rat liver homogenate was $4660 \mu \mathrm{g}$ (Fig 4A). A similar effect was produced by $5350 \mu \mathrm{g}$ of ascorbic acid. The quantity of the extract needed for 50 $\%$ inhibition of brain lipid peroxidation was 3780 $\mu \mathrm{g}$. A similar effect was produced by $4690 \mu \mathrm{g}$ of ascorbic acid (Fig 4B).
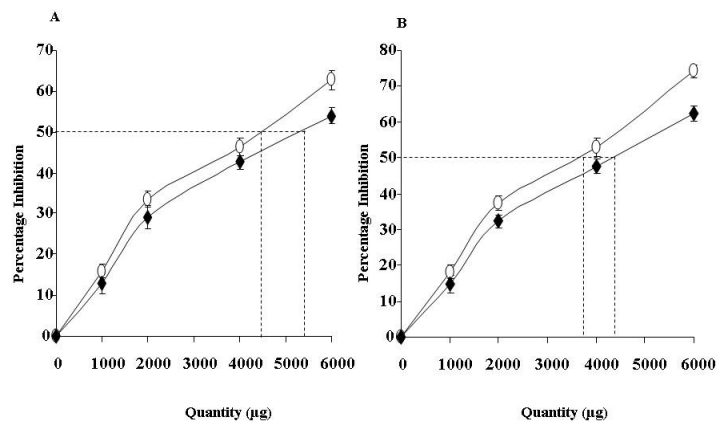

Fig 4: Effect of $C$. sativum on the in vitro inhibition of lipid peroxidation in liver and brain of rat $(n=6)$. Graphical representations of the concentrations of C. sativum and ascorbic acid required to inhibit 50 percent of lipid peroxidation in liver $(A)$ and brain (B) homogenates. $\mathrm{O}=C$. sativum and $\bullet=$ ascorbic acid. 


\section{DISCUSSION}

Functional foods and food additives for improving quality of life have received a lot of attention in recent times. Spices and condiments widely recognized as food additives have been used traditionally to prevent and treat diseases.

The results from this study show that administration of $C$. sativum aqueous extract had a profound influence on the urinary levels of VMA and ascorbic acid in rats subjected to forced swim stress. The extract also improved memory deficits induced by scopolamine injection and exhibited higher inhibition of lipid peroxidation when compared with ascorbic acid in both rat liver and brain homogenates.

It is well known that noradrenaline and adrenaline, which are released normally or in response to stress are metabolized into 3methoxy 4-hydroxyphenyl glycol (MOPEG) centrally and vanillyl mandelic acid (VMA) peripherally. During increased stress, blood levels of VMA increase, leading to the excretion of the metabolite in the urine [17].

L-ascorbic acid which is synthesized from Dglucose in rats is altered in body fluids due to several factors like age, exposure to environmental situations, stress and diet etc. Ascorbic acid is present in adrenal glands as a metabolite of glucose in rats and glucaric acid is the corresponding metabolite in humans and primates. Several studies indicated that the tissue levels of ascorbic acid decrease on application of stress [18, 19]. Furthermore ascorbic acid being a free radical scavenger, it is more likely utilized in scavenging the free radicals involved in stress resulting in its decreased urinary concentration and also it has role in the biosynthesis of noradrenaline as a cofactor in the conversion of dopamine to noradrenaline [20]. These findings justify the use of urinary VMA ascorbic acid levels during stress as indirect biochemical indices for studying the anti-stress activity of $C$. sativum.
Several reports suggested that medicinal plants with immense antioxidant properties might be beneficial in combating stress [21, 22]. Stress and free radicals have been implicated in loss of memory and cognitive deficits [2, 3, 23]. Earlier reports indicated that scopolamine impaired retrieval memory of rats [24, 25]. The amnesia was associated with a significant increase in oxidative stress as indicated by rise in brain thiobarbituric acid reactive species (TBARS) with elevated MDA and reduced glutathione (GSH) levels. Ideally, scopolamine induced amnesia in rats could be used as a valid model to screen agents with potential therapeutic benefit in dementia [26].

The mechanism by which C.sativum extract acts in attenuating the memory deficits induced by scopolamine could be due to its free radical scavenging activity. Furthermore, the antioxidant activity of the $C$. sativum extract provide mechanistic basis in relieving stress by way of combating oxidative damage.

\section{CONCLUSION}

The present study provides scientific support for anti-stress, antioxidant and anti-amnestic activities of C.sativum extract and usage in the management of stress and stress-related diseases like memory loss may be of great interest.

\section{ACKNOWLEDGEMENT}

This work was supported by Konkuk University in 2011.

\section{REFERENCES}

1. Rai D, Gitika BG, Sen T, Palit G. Anti $\square$ stress effects of Ginkgo biloba and Panax ginseng: a comparative study. J Pharmacol Sci 2003; 93: 458-464.

2. Kim JJ, Diamond DM. The stressed hippocampus, synaptic plasticity and lost memories. Nat Rev Neurosci 2002; 3: 453-462.

3. Sandi C. Stress cognitive impairment and cell adhesion molecules. Nat Rev Neurosci 2004; 5: $917-930$.

Trop J Pharm Res, February2012;11 (1): 41 
4. Demopoulos HB, Pietronigro KK, Deligman ML. The development of secondary pathology with free radical reactions as a threshold mechanism. $J$ Am Coll Toxicol 1983; 3: 173-184.

5. Tapsell LC, Hemphill I, Cobiac L, Patch CS, Sullivan $D R$, Fenech $M$, Roodenrys $S$, Keogh JB, Clifton PM, Williams PG, et al. Health benefits of herbs and spices: the past, the present, the future. Med J 2006; 185: S4-S24.

6. Wu TT, Tsai CW, Yao HT, Lii CK, Chen HW, Wu YL, Chen PY, Liu KL. Suppressive effects of extracts from the aerial part of Coriandrum sativum $L$. on LPS-induced inflammatory responses in murine RAW 264.7 macrophages. J Sci Food Agric 2010; 90: 1846-1854.

7. Mani V, Parle M, Ramasamy K, Majeed ABA. Reversal of memory deficits by Coriandrum sativum leaves in mice J Sci Food Agric 2011; 91: 186-192.

8. Sushruta $K$, Satyanarayana $S$, Srinivas N, Raja Sekhar J. Evaluation of the blood-glucose reducing effects of aqueous extracts of the selected umbelliferous fruits used in culinary practices. Trop J Pharm Res 2006; 5: 613-617.

9. Jabeena $Q$, Bashira $S$, Lyoussi $B$, Gilani $A H$. Coriander fruit exhibits gut modulatory, blood pressure lowering and diuretic activities. J Ethnopharmacol 2009; 122: 123-130.

10. Aissaoui A, El-Hilaly J, Israili ZH, Lyoussi B. Acute diuretic effect of continuous intravenous infusion of an aqueous extract of Coriandrum sativum $L$. in anesthetized rats. $J$ Ethnopharmacol 2008; 115: 89-95.

11. Derrell C. Guide for the care and use of laboratory animals. Institute of Laboratory Animal Resources. National Academy Press, Washington DC, USA, 1996.

12. Nagaraja $H A$, Jaganathan $P S$. Influence of different types of stress on selected cardiovascular parameters in rats. J Physiol Pharmacol 1999; 43: 296-304.

13. Pisano JJ, Crout JR, Abraham A. Determination of 3methoxy, 4-hydroxymandellic acids in urine. Clin Chim Acta 1962; 7: 277-284.

14. Roe JH, Kuehter CA. The determination of ascorbic acid in bile, blood and urine through 2, 4 dinitrophenylhydrazine derivatives of dehydroascorbic acid. J Biol Chem 1943; 147: 399-408.

15. Cook L, Weidley E. Behavioural effects of some psychopharmacological agents. Ann NY Acad Sci 1957; 66: 740-752.
16. Ohkawa $H$, Ohishi $N$, Yagi K. Assay for lipid peroxides in animal tissues by thiobarbituric acid reaction. Anal Biochem 1979; 95: 351 358.

17. Ion M. Urinary excretion of catecholamines and vanillyl mandelic acid in rats exposed to cold. Acta Physiol Scand 1969; 76: 393-395.

16. Goodman GA. The pharmacological basis of therapeutics. (10th ed). McGraw-Hill: New York, 2001; 1804-1805.

19. Kutlu HR, Forbes JM. Changes in growth and blood perameters in heat stressed broiler chicks in response to dietary ascorbic acid. Liverstock Prod Sci. 1993; 36: 335-350.

20. Cheng TK, Coon CN, Hamre ML. Effect of environmental stress on the ascorbic acid requirement of laying hens. Pult Sci 1990; 69: 774-780.

21. Sreemantula S, Nammi S, Kolanukonda R, Koppula $S$, Boini KM. Adaptogenic and nootropic activities of aqueous extract of Vitis vinifera (grape seed): an experimental study in rat model. BMC Complement Alternat Med 2005; 5: 1-8.

22. Koppula S, Choi DK. Anethum graveolens Linn (Umbelliferae) extract attenuates stressinduced urinary biochemical changes and improves cognition in scopolamine-induced amnesic rats. Trop J Pharm Res 2011; 10: 4754

23. Esch T, Stefano GB, Fricchione GL, Benson H. The role of stress in neurodegenerative diseases and mental disorders. Neuroendocrinol Lett 2002; 23: 199-208.

24. Sarter M, Bodewitz G, Stephens DN. Attenuation of scopolamine-induced impairment of spontaneous alteration behaviour by antagonist but not inverse agonist and agonist beta-carbolines. Psychopharmacol 1988; 94: 491-495.

25. Sunderland T, Tariot $P N$, Weingartner $H$, Murphy $D L$, Newhouse PA, Mueller EA, et al. Pharmacologic modelling of Alzheimer's disease. Prog Neuropsychopharmacol Biol Psychiatry 1986; 10: 599-610.

26. El-Sherbiny DA, Khalifa AE, Attia AS, Eldenshery El $D$. Hypericum perforatum extract demonstrates antioxidant properties against elevated rat brain oxidative status induced by amnestic dose of scopolamine. Pharmacol Biochem Behav 2003; 76: 525-533. 